\title{
Three-Dimensional Evaluation of Root Canal Morphology in Lower Second Premolars of Early and Middle Pleistocene Human Populations From Atapuerca (Burgos, Spain)
}

\author{
Leyre Prado-Simón, ${ }^{1,2 *}$ María Martinón-Torres, ${ }^{1}$ Pilar Baca ${ }^{2}$ Anthony J. Olejniczak, ${ }^{1}$ \\ Aida Gómez-Robles, ${ }^{3}$ María Lapresa, ${ }^{1}$ Juan Luis Arsuaga, ${ }^{4}$ and José María Bermúdez de Castro ${ }^{1}$ \\ ${ }^{1}$ Dental Anthropology Group, National Research Centre on Human Evolution (CENIEH), Burgos, Spain \\ ${ }^{2}$ Stomatology Department, Dentistry Faculty, University of Granada, Spain \\ ${ }^{3}$ Konrad Lorenz Institute for Evolution and Cognition Research, Altenburg, Austria \\ ${ }^{4}$ Centro Mixto UCM-ISCIII de Evolución y Comportamientos Humanos, Madrid, Spain
}

\section{KEY WORDS root canal; microtomography; hominin taxonomy; LP4; Atapuerca}

\begin{abstract}
The aim of this study is to describe the morphology of the roots and root canals of permanent lower second premolars (LP4s) with fully developed roots of five hominin groups: Homo sp. (ATE9-1 specimen) from Atapuerca-Sima del Elefante locality, $H$. antecessor (ATD6-4 and ATD6-125) from Atapuerca-Gran Dolina TD6 locality, $H$. heidelbergensis from Atapuerca-Sima de los Huesos locality, $H$. neanderthalensis from Krapina, Regourdou, and Abri Bourgeois-Delaunay localities, and two contemporary $H$. sapiens groups. The teeth were scanned by means of microtomography. The roots were divided into three virtual segments by three planes: cemento-enamel junction (CEJ), mid-root (MR), and mid-apex (MA). Volumetric and planar direct measurements of the whole teeth and each segment were taken. Descriptive statistical analyses and nonparametric Mann-Whiney
\end{abstract}

Due to their durability relative to other hard tissues, dental elements have a greater chance of fossilizing. Teeth therefore constitute the majority of fossil hominid collections (e.g., Hillson, 1996). The development, thickness, and external morphological details of hominoid and hominin teeth have been extensively studied over the last century. Our understanding of the diet, life history, and phylogenetic relationships of fossil hominin species has been largely based on studies quantifying enamel thickness (e.g., Kay, 1981; Martin, 1985), tooth microwear and microtexture (e.g., Scott et al., 2005), enameldentine junction shape (e.g., Korenhof, 1961; Skinner et al., 2008, 2009; Bailey et al., 2011), tooth roots (e.g., Abbot, 1984; Wood et al., 1988; Kupczik and Hublin, 2010) and the incremental development of these dental tissues (e.g., Dean et al., 2001; Lacruz and Bromage, 2006; Smith et al., 2007).

The space inside the dentine containing the pulp (vascular and nervous tissues) is known as the pulp cavity, while the canals of the pulp cavity that are inside the roots are known as the root canals. This system serves as a conduit for the vascular and nervous tissues (Wright, 2007), and its contour reflects, in general, the external contour of the tooth (Cohen and Hargreaves, 2008). The pulp cavity has received little attention in paleoanthropology. Although some aspects of morphology test were performed to test for significant differences $(P<0.025)$ between groups. ATE9-1 and Gran DolinaTD6 fossils present intricate radicular complexes that might be transitional between the morphologies of Australopithecus robustus and African early Homo and the derived conditions typically found in later Homo. In $H$. neanderthalensis and $H$. heidelbergensis, the root canals are wide, with small apical convergence. This trait is particularly pronounced in the Sima de los Huesos sample which may reflect a particularity of this population. Our study demonstrates the potential of hominin roots and root canals as untapped sources of taxonomic information when the tooth crown is fragmented. Future studies, including more fossil specimens and species will shed light in the polarity of the morphologies observed. Am J Phys Anthropol 147:452461, 2012. ๑ 2012 Wiley Periodicals, Inc.

related to the morphology of this internal space (e.g., taurodontism) are often discussed (e.g., Harvati et al., 2003; Rosas et al., 2006), and some studies of the threedimensional hominin pulp cavity proportions have been performed (e.g., Bayle et al., 2009a,b, 2010; Kupczik and Hublin, 2010), the pulp cavity has been largely overlooked by paleoanthropological scholars. In paleoanthropological studies, the main reason for the analysis of the pulp cavity has been the assessment of taurodontism (e.g., Trinkaus, 1978; Harvati et al., 2003; Rosas et al.,

\footnotetext{
Grant sponsors: Atapuerca Foundation and the Spanish Ministry of Science and Innovation (Project number: CGL2009-12703-C03-01, 02, and 03) and Junta de Castilla y León (Proyecto Grupo de Exce-
} lencia GR249).

\footnotetext{
*Correspondence to: Leyre Prado Simón, Dental Anthropology Group, National Research Centre on Human Evolution (CENIEH), Paseo Sierra de Atapuerca s/n, 09002 Burgos, Spain.

E-mail: leyreps@gmail.com
}

Received 20 October 2010; accepted 14 December 211

DOI 10.1002/ajpa.22015

Published online 27 January 2012 in Wiley Online Library (wileyonlinelibrary.com). 
TABLE 1. Hominin lower second premolar with completely developed roots

\begin{tabular}{|c|c|c|c|c|}
\hline Species & Origin & Sample & $n$ & Wear (Molnar, 1971) \\
\hline Homo sp. & Sima del Elefante & Total $^{\mathrm{a}}$ & 1 & $4(n=1)$ \\
\hline H. antecessor & Gran Dolina TD6 & Total $^{\mathrm{a}}$ & 2 & $1(n=2)$ \\
\hline \multirow[t]{2}{*}{ H. heidelbergensis } & Sima de los Huesos & Total $^{\mathrm{a}}$ & 14 & $\begin{array}{l}2(n=7) \\
3(n=7)\end{array}$ \\
\hline & & Subsample ${ }^{\mathrm{b}}$ & 7 & $\begin{array}{l}2(n=4) \\
3(n=3)\end{array}$ \\
\hline \multirow[t]{2}{*}{ H. neanderthalensis } & Krapina & Total $^{\mathrm{a}}$ & 5 & $\begin{array}{l}2(n=4) \\
3(n=1)\end{array}$ \\
\hline & $\begin{array}{l}\text { Regourdou } \\
\text { Bourgeois-Delaunay }\end{array}$ & $\begin{array}{l}\text { Subsample }^{\mathrm{b}} \\
\text { Total }^{\mathrm{a}} \text { and Subsample } \\
\text { Total }^{\mathrm{b}} \text { and Subsample }\end{array}$ & $\begin{array}{l}2 \\
1 \\
2\end{array}$ & $\begin{array}{l}2(n=2) \\
2(n=1) \\
2(n=2)\end{array}$ \\
\hline \multirow[t]{2}{*}{ H. sapiens } & San Pablo collection & Total $^{\mathrm{a}}$ and Subsample ${ }^{\mathrm{b}}$ & 18 & $\begin{array}{l}2(n=11) \\
3(n=4) \\
4(n=3)\end{array}$ \\
\hline & CENIEH dental collection & Total $^{\mathrm{a}}$ and Subsample ${ }^{\mathrm{b}}$ & 5 & $\begin{array}{l}2(n=3) \\
3(n=1) \\
4(n=1)\end{array}$ \\
\hline
\end{tabular}

a The total sample was composed by all the hominin premolars with completely developed roots.

b The subsample was formed by premolars with roots in perfect state of preservation (with no cracks or imperfections). This sample was used for the whole root quantitative measurements.

2006). It is still unknown whether quantification of the shape and size of this internal space is useful for hominin taxonomy.

The morphology of mandibular premolars has been proved to be taxonomically diagnostic among hominin taxa (Ludwig, 1957; Patte, 1962; Biggerstaff, 1969; Wood and Uytterschaut, 1987; Uytterschaut and Wood, 1989; Bailey, 2002a,b; Bailey and Lynch, 2005; MartinónTorres et al., 2006; Gómez-Robles et al., 2008). In particular, the morphology of the lower second premolar (LP4) has been described as useful for taxonomic differentiation of Pleistocene hominins (e.g., Bailey and Lynch, 2005; Martinón-Torres et al., 2006). LP4s have been chosen for this study because of their higher morphological stability and lower variation in the external root and root canal morphology in comparison with the LP3 (e.g., Sprinz, 1953; Soares and Goldberg, 2002; Cohen and Hargreaves, 2008). Furthermore, LP4s were the only tooth class available in all the hominin species analyzed and will potentially allow us to identify morphological trends among related lineages.

The unique ability of microcomputed tomography (micro-CT) to accurately visualize internal dental structures through the nondestructive production of virtual planes of sections and three-dimensional renderings facilitates the preservation of valuable fossil and museum collections that are otherwise unavailable for destructive sampling (e.g., Kono, 2004; Tafforeau, 2004; Olejniczak and Grine, 2006).

The aim of the present study is to describe the morphology of the roots and root canal system of lower permanent second premolars (LP4) of some fossil and modern specimens such as the Atapuerca-Sima del Elefante specimen attributed to Homo sp., some specimens recovered from the Gran Dolina-TD6 level of Atapuerca assigned to $H$. antecessor, several LP4s from the Sima de los Huesos (SH) site (Sierra de Atapuerca) assigned to $H$. heidelbergensis, a sample of $H$. neanderthalensis specimens recovered from different European localities and a sample of modern $H$. sapiens, using an accurate and nondestructive method based on microtomographic imaging and investigate possible taxonomic features. If the roots and root canals of LP4s prove to have speciesspecific morphological features that could be used as taxonomic indicators, future studies should address the reconstruction and comparison of the pulp cavity of other tooth positions and a larger range of taxa. Ultimately, this would support taxonomic assessments and improve taxonomic resolution in cases where only worn, broken, isolated dental remains are available for study.

\section{MATERIALS AND METHODS Materials}

Lower second premolars from four fossil hominin groups and two modern human populations were used in this study (Table 1). The ATE9-1 specimen from Sima del Elefante (Carbonell et al., 2008), recently classified as Homo sp. (Bermúdez de Castro et al., 2011), and the specimens ATD6-4 and ATD6-125 attributed to $H$. antecessor from Gran Dolina-TD6 level (Bermúdez de Castro et al., 2008) are the only dental remains available so far for the early Pleistocene in the European continent (Bermúdez de Castro et al., 2004, 2011; Carbonell et al., 2008). Furthermore, the study includes 14 specimens assigned to $H$. heidelbergensis recovered from the Sima de los Huesos locality (Bermúdez de Castro 1988, 1993; Arsuaga et al., 1993, 1997; Bermúdez de Castro and Nicolás, 1995) which provided the largest hominin collection world wide for the Middle Pleistocene. We have also included eight $H$. neanderthalensis specimens from Krapina (Monge et al., 2008), Regourdou (Vandermeersch and Trinkaus, 1994; Maureille et al., 2001), and Abri Bourgeois-Delaunay (Condemi, 2001; Macchiarelli et al., 2006). Finally, we have included in the sample two $H$. sapiens samples, a medieval modern human collection from the site of San Pablo (Burgos, Spain), and the CENIEH's dental collection, composed of clinically extracted teeth from patients of known age and sex, representing a modern Spanish population (Table 1).

\section{Methods}

Exclusion criteria. An exhaustive selection of LP4s was carried out. Only permanent teeth with completely developed roots were included in the study. All the premolars of the sample that fulfilled this requirement 

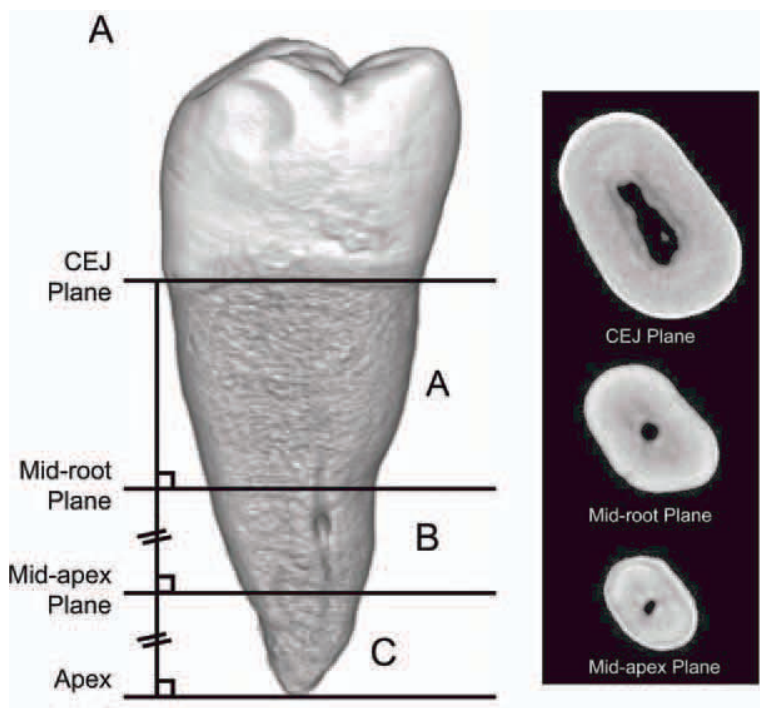

B

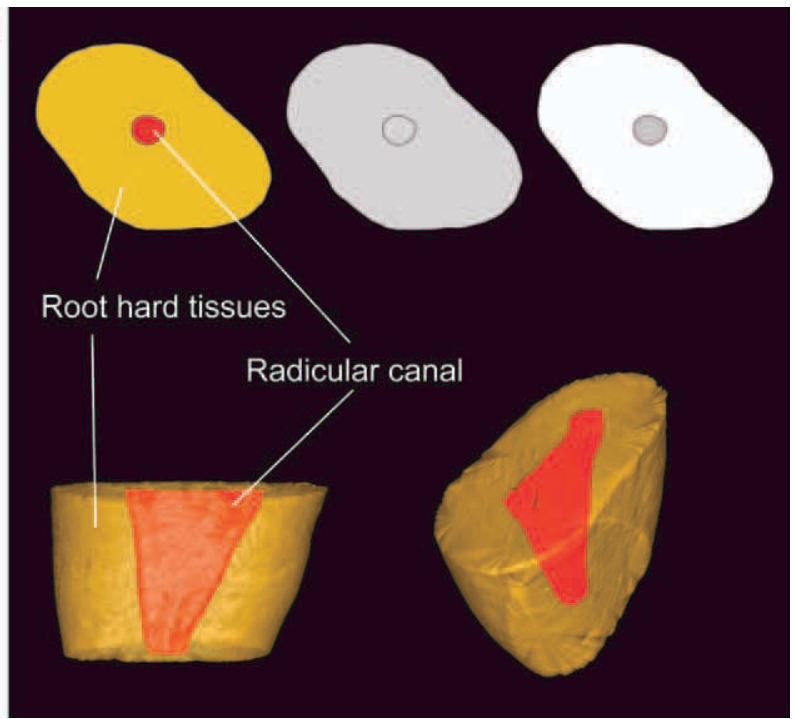

Fig. 1. A: Diagram showing the two-dimensional planes of section and the three-dimensional root sections studied here. The cemento-enamel junction (CEJ) plane is defined as the best-fit plane through the CEJ, determined in three dimensions (see text). The midroot plane is parallel to the CEJ plane, and is located at the midpoint of the CEJ plane and the root apex. The midapex plane is also parallel to the CEJ plane, and is located midway between the midroot plane and the root apex. These three-dimensional root sections contained between the planes are named "section A" (between the CEJ plane and the mid-root plane), "Section B" (between the mid-root plane and the mid-apex plane), and "section C" (between the midapex plane and the root apex). B: The diagrams show a schematic representation of the CEJ plane (upper left), in which the root hard tissues (gold) and the pulp cavity (red) are distinguished. The measurement of the total area of the planes is depicted at the center of the top row (the gray area; this measurement includes the area of the contained root canal). The measurement of the area of the root canal is depicted in gray in the upper right figure. The figures in the bottom row show a representation of volumetric root section $\mathrm{A}$, in which the hard tissues (semitranslucent gold) are distinguished from the root canal (red).

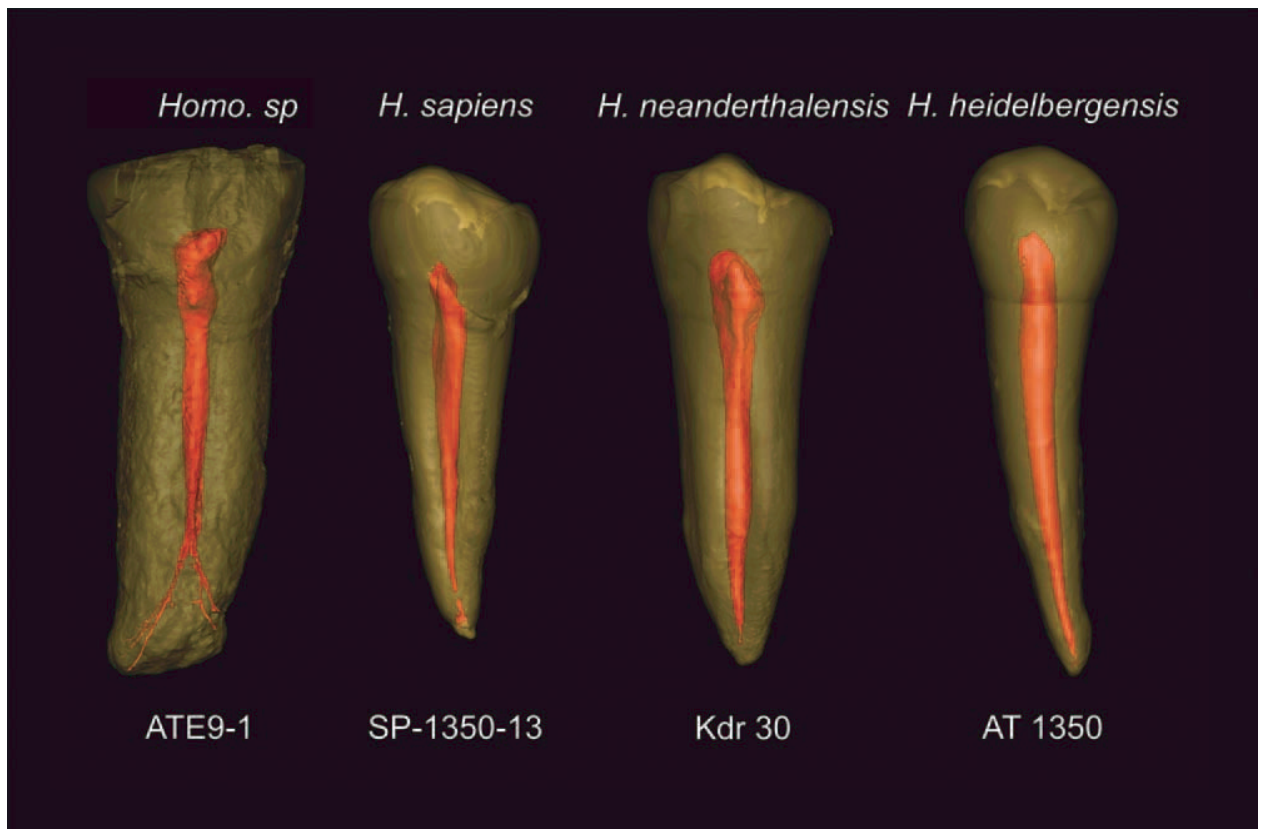

Fig. 2. Three-dimensional models of the buccal orientation of the representative lower second premolars of the four species studied here; the teeth are not depicted to scale, the pulp cavities have been made to be of uniform height for ease of interpretation. Differences in the morphology of the root canal are apparent between species. The marked convergence of the $H$. sapiens root canal walls contrasts with the less pronounced convergence of the $H$. heidelbergensis root canal walls.

comprised the study sample, which was used for qualitative descriptions of the roots and pulp cavity and for quantitative measurements of the cemento-enamel junction plane (CEJ plane). A subsample of premolars with roots in a perfect state of preservation (with no cracks or imperfections) was selected for quantitative measurements of the whole root and root canals. The species, paleoanthropological sites, total sample and subsample 
TABLE 2. Description of the measurements taken for the study

\begin{tabular}{|c|c|c|c|}
\hline \multicolumn{3}{|l|}{ Measurements } & \multirow{2}{*}{$\begin{array}{l}\text { Acronym } \\
\text { Totlength }\end{array}$} \\
\hline Root & Total & Length of the root in $\mathrm{mm}$ & \\
\hline & & Surface area of the entire root in $\mathrm{mm}^{2}$ & Totsf \\
\hline & & Volume of the entire root in $\mathrm{mm}^{3}$ & Totvol \\
\hline & Root sections & $\begin{array}{l}\text { Surface area of each three-dimensional root section } \\
\text { in } \mathrm{mm}^{2}\end{array}$ & Sf A, B, and C \\
\hline & & Volume of each three-dimensional root section in $\mathrm{mm}^{3}$ & Vol A, B, and C \\
\hline & $\begin{array}{l}\text { Two-dimensional } \\
\text { planes }\end{array}$ & $\begin{array}{l}\text { Total cross-sectional area of the two-dimensional plane } \\
\text { in } \mathrm{mm}^{2}\end{array}$ & AreaCEJ, MR, and MA \\
\hline \multirow[t]{5}{*}{ Root can als } & Total & Surface area of the entire pulp cavity of the root in $\mathrm{mm}^{2}$ & Totpulpsf \\
\hline & & Volume of the entire pulp cavity of the root in $\mathrm{mm}^{3}$ & Totpulpvol \\
\hline & Root sections & $\begin{array}{l}\text { Surface area of the pulp cavity in each three-dimensional } \\
\text { root section in } \mathrm{mm}^{2}\end{array}$ & PulpsfA, B, and C \\
\hline & & $\begin{array}{l}\text { Volume of the pulp cavity in each three-dimensional } \\
\text { root section in } \mathrm{mm}^{3}\end{array}$ & PulpvolA, B, and C \\
\hline & Two-dimensional planes & $\begin{array}{l}\text { Total cross-sectional area of the pulp cavity contained in } \\
\text { the two-dimensional plane in } \mathrm{mm}^{2}\end{array}$ & PulpareaCEJ, MR, and MA \\
\hline
\end{tabular}

sizes as well as the category of wear of each tooth are presented in Table 1.

The category of wear for each tooth was determined following Molnar's (1971) method. This method has eight categories of wear sorted by tooth type (incisors, premolars, and molars). Category 1 corresponds to unworn crowns, while Category 8 represents roots functioning as occlusal surfaces due to the complete wear of the dental crown.

Microtomographic protocol. With the exception of the $H$. neanderthalensis premolars, all the teeth were scanned with a Scanco microtomographic system housed at the National Research Centre for Human Evolution in Burgos, Spain ( $\mu$ CT 80, Scanco Medical, Switzerland) using the following settings for each scan: voltage $=70$ $\mathrm{kV}$, amperage $=140 \mathrm{~mA}$, angular increment $=0.72^{\circ}$, and resultant isometric voxel size $=36 \mu \mathrm{m}^{3}$ (except the ATE9-1 from the Sima del Elefante locality which was scanned with a resultant isometric voxel size of $20 \mu \mathrm{m}^{3}$ ). Microtomographic scans of the $H$. neanderthalensis premolars were obtained from the NESPOS database (available at: https://nesposlive01.pxpgroup.com), which makes micro-CT scans available to members. These scans have isometric voxel sizes ranging between 20 and $45 \mu \mathrm{m}^{3}$. The premolars obtained from Regourdou and Abri Bourgeous Delaunay localities were scanned with the European Synchrotron Radiation Facility, Beamline ID 17, Grenoble, France.

Imaging processing. This study produced both twodimensional planes and three-dimensional sections of the tooth roots (see Fig. 1). Images resulting from microCT scanning were cropped three-dimensionally with the ImageJ software package (NIH) to eliminate background space and reduce the file size. The images were then reoriented with the Voxblast 3D software (Vaytek, Inc.) to ensure the selection of homologous planes. These images were then imported into the MIMICS 13.1 software package (Materialise). The root and the crown of the premolars were separated for the measurements at the CEJ plane and only the root and the root canals were used for the study. The root was divided into three segments based on Kvaal et al. (1995) with some modifications. The cementoenamel junction plane (CEJ) was located following Olejniczak (2006). Next, the mid-root plane (MR), equivalent to Kvaal's section "C," was defined as parallel to CEJ and midway between CEJ and the root apex. Finally, the midapex plane (MA), which is also parallel to the CEJ and MR planes, was defined at the midpoint of the MR plane and the root apex (see Fig. 1). For clarity in the following sections, the three-dimensional root sections contained between each of the planes defined above have been named as follows:

1. $3 \mathrm{D}$ root section $\mathrm{A}$ is the volume contained between CEJ and MR.

2. $3 \mathrm{D}$ root section $\mathrm{B}$ is the volume contained between $\mathrm{MR}$ and MA.

3. $3 \mathrm{D}$ root section $\mathrm{C}$ is the volume contained between MA and the root apex.

Two-dimensional and three-dimensional direct measurements were recorded for each of the teeth scanned (Table 2). The direct measurements were taken to obtain the absolute values of the size (volume, surface area) of the root and root canals in all planes and sections. When two root canals were present in one of the three planes, the sum of the measurements of both canals was taken.

Qualitative morphological descriptions. The roots of the LP4s of the whole sample were described using Wood et al. (1988) categories and the pulp cavities were described following the detailed description found in Canalda and Brau (2006).

Descriptive statistical analyses. Basic descriptive statistical analyses were applied to the sample (CEJ plane measurements) and the subsample (whole root and root canal measurements) organized by species where the mean and standard deviation were calculated (Tables 3 and 4).

Interspecific comparisons. Comparisons between the two-dimensional and three-dimensional direct measurements were applied to the subsamples of $H$. heidelbergensis, $H$. neanderthalensis, and $H$. sapiens. Nonparametric Mann-Whitney test was used for the comparisons to test for significant differences $(P<0.025)$ between the variables. Species was used as the grouping variable (Tables 3 and 4). All the statistical analyses performed were done using PASW Statistics 18 software (SPSS Science, Inc.).

\section{RESULTS \\ Qualitative morphological descriptions and comparisons}

A three-dimensional rendering model of the whole tooth and the pulp cavity of an LP4 for each of the species stud- 

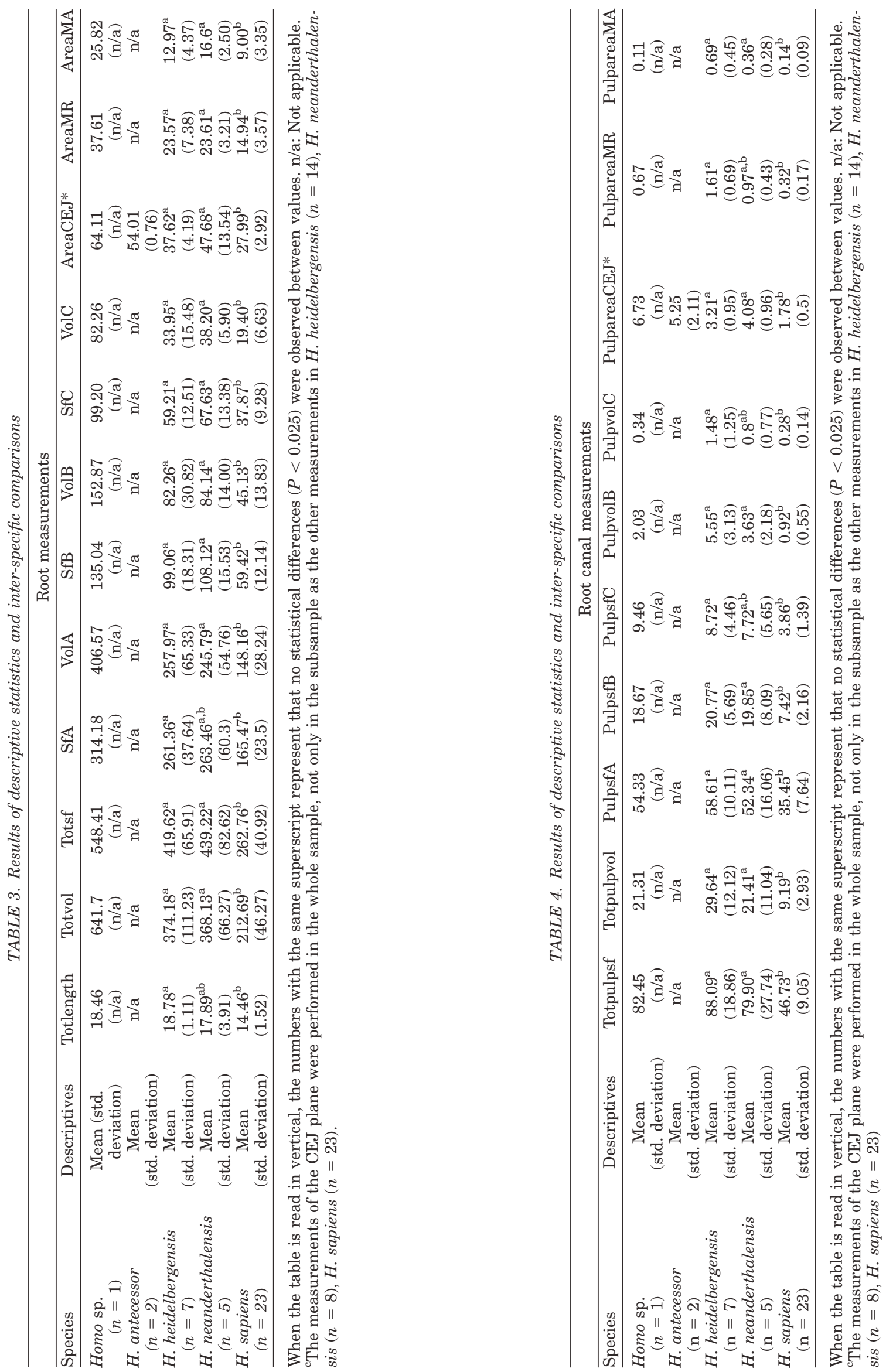
ied is shown in Figure 2. Externally, ATE9-1 from the Sima del Elefante locality presents a Tomes' root (2T). Inside, the root canal is bifurcated at the apical third of the root into two canals (MB and $\mathrm{DL}$ ) that disappear to form a ramification at the apex. The transversal section of the root canal at the CEJ plane is circular.

The two $H$. antecessor premolars from the Gran Dolina-TD6 locality showed two roots $(2 \mathrm{R}$ : MB $+\mathrm{DL})$ classified as Tomes' root Grade 5 (Turner et al., 1991) with total bifurcation and separation of the radicals in the apical third. Internally we can identify two separated root canals, one $\mathrm{MB}$ and one $\mathrm{DL}$ at the coronal third. In ATD6-4, the MB canal bifurcates from before the apical third into a buccal (B) and a DL canal. In ATD6-125 the apical thirds of the roots are broken so we cannot assess if the MB canal bifurcated in two as it happens in ATD6-4. Internally we can identify two separated root canals, one $\mathrm{MB}$ and one $\mathrm{DL}$ at the coronal third. In ATD6-4, the MB canal bifurcates at the middle third into a buccal (B) and a DL canals. In ATD6-125 the apical third of the roots are partially fractured so we cannot assess if the MB canal bifurcated in two as it happens in ATD6-4. The transverse section of the root canal at the CEJ plane is ellipsoid.

All premolars from the $H$. heidelbergensis sample showed a single root (1R) and one canal with a slightly convergent (almost parallel) longitudinal section and circular transverse section at the CEJ plane.

All the $H$. neanderthalensis premolars showed a single root (1R) with one canal except for the Krapina specimen (Kdr 35) that had a bifurcated root canal (starting at the coronal third of the root). The rest of the premolars analyzed, had just a single canal markedly convergent to the apex that followed the curvature of the root. Only one showed a mesio-lingual bifurcation at the apical third. All the premolars showed an ellipsoid transverse caliber at the CEJ plane.

The "San Pablo" medieval modern human sample showed more homogeneity in root canal morphology. All the premolars studied from this population had a single root $(1 R)$ and one root canal with a highly convergent longitudinal section and an ellipsoid transversal section at the CEJ plane.

Similarly, all the premolars in the CENIEH's modern dental collection have a single root (1R) in the Wood et al. (1988) classification. Nevertheless, when looking at their internal morphology, cases of a bifurcated canal or a single canal, bifurcated at the middle third and posteriorly fused at the apical third were observed; some of them showed primary transverse canals, primary blind oblique canals, or recurrent canals. The longitudinal section of the canals was highly convergent toward the apex. In addition, the transverse section at the CEJ showed an ellipsoid shape.

\section{Descriptive statistics}

Tables 3 and 4 show the mean and standard deviation of each of the sample and subsample. In all cases, there was a decreasing size-related trend from the two-dimensional and three-dimensional measurements taken at the CEJ plane to the measurements taken at the MA plane.

$H$. heidelbergensis showed the highest mean values for root length (Totlength) and root volume (Totvol) using the external measurements of the root, followed by $H$. neanderthalensis and $H$. sapiens. $H$. neanderthalensis showed the highest mean value of total root surface (Totsf) followed by $H$. heidelbergensis and $H$. sapiens. This trend was also followed when the teeth were analyzed according to their three-dimensional root sections (Vol and SfA, B, and C). H. heidelbergensis showed the highest mean value of VolA, followed by $H$. neanderthalensis and $H$. sapiens. Regarding the two-dimensional external root measurements of the planes, $H$. neanderthalensis showed the highest mean value in the area of the CEJ MR and MA planes followed by $H$. heidelbergensis and $H$. sapiens.

Regarding the whole root canal measurements and the measurements of the pulp 3D sections (Totpulvol, Totpulpsf, Pulpvol and PulpsfA, B and C), H. heidelbergensis showed the highest mean values followed by $H$. neanderthalensis and $H$. sapiens. When looking at the two-dimensional measurements of the root canals (PulpareaCEJ, MR and MA), H. neanderthalensis showed the highest mean values at the CEJ plane followed by $H$. heidelbergensis and $H$. sapiens. $H$. heidelbergensis showed the highest mean values for the other two planes (PulpareaMR and PulpareaMA), followed by $H$. neanderthalensis and $H$. sapiens.

\section{Interspecific comparisons}

The results of the interspecific comparisons are presented in Tables 3 and 4 . Significant differences $(P<$ 0.025) were observed between all the measurements when comparing $H$. sapiens and $H$. heidelbergensis. $H$. sapiens and $H$. neanderthalensis showed significant differences $(P<0.025)$ in all the variables compared except Totlenght, PulpvolC, PulpareaMR, and PulpsfA and C. No significant differences were observed between the variables compared in $H$. heidelbergensis and $H$. neanderthalensis.

\section{DISCUSSION}

The roots and the root canals of the LP4s were described and analyzed in this study as their morphology has been described as particularly useful for taxonomic differentiation of Pleistocene hominins (e.g., Bailey and Lynch, 2005; Martinón-Torres et al., 2006). The LP4s also show higher morphological stability and lower variation in external root and root canal morphology in comparison with the LP3 (e.g., Sprinz, 1953; Soares and Goldberg, 2002; Cohen and Hargreaves, 2008).

It has been suggested that the variation in premolar root number may constitute a genetic polymorphism linked to phylogenetic differences in Plio-Pleistocene hominins (Abbot, 1984; Wood et al., 1988). The primitive root form for LP4s found in Australopithecus robustus and African early Homo (Wood et al., 1988) is 2R: M + $\mathrm{D}$ (mesial and distal roots with two differentiated canals in each root). This primitive condition presents at least two trends in root morphology. One trend seems to lead toward root reduction (1R: one single root with a single canal), and the other to root elaboration also called $2 \mathrm{R}$ : $\mathrm{M}+\mathrm{D}$ (mesial and distal roots with one root canal in each root). The LP4s of $H$. heidelbergensis, $H$. neanderthalensis, and $H$. sapiens (with only few exceptions noted below) showed derived root morphologies (1R) with regard to Australopithecus robustus and African early Homo (Wood et al., 1988). In contrast, ATE9-1 and $H$. antecessor showed different degrees of Tomes' root leading to the complete separation of the roots in the 


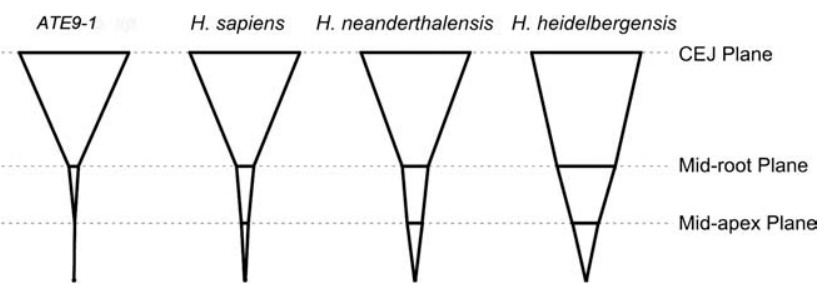

Fig. 3. Schematic diagrams of the area of the root canal at the three planes of section recorded in this study; these data are based on the mean values recorded for each species. The width of the line at the top of each diagram represents the area of root canal in the CEJ plane of section; this has been standardized to be equal in all the species for the purposes of this diagram. The lines below the CEJ plane represent the area of the root canal at MR and MA planes relative to the area of pulp at the CEJ plane. Interspecies differences are apparent in the rate of convergence of the walls surrounding the root canals toward the root apex; $H$. heidelbergensis shows the most parallel walls of the root canal.

apical third in the latter. It has been suggested that the Tomes' root in lower second premolars could represent a transitional morphology from a double rooted tooth to the derived form (1R) as the evolutionary consequence of a struggle to maintain a large root surface area despite a decrease in the number of roots (Shields, 2005). The roots and root canals of the two $H$. antecessor premolars from the Gran Dolina-TD6 sample used in this study were classified as $2 \mathrm{R}$ with $\mathrm{MB}+\mathrm{DL}$ roots with two (at the coronal half) and three canals (at the apical third) by bifurcation of the MB plate-like root (although the latter cannot be confirmed in ATD6-125 as it is fractured in its distal end). This finding is coincident with the morphology already described by Bermúdez de Castro et al. (1999), which was suggested as possible uniquely derived condition to this species (Bermúdez de Castro et al., 1999). Similarly, ATE9-1 canals present a similar type of bifurcation (2R: $\mathrm{MB}+\mathrm{DL})$ although closer to the apex.

Figure 3 is based in the mean values obtained for each segment and represents graphically the root canal morphologies observed in the studied hominin groups. Although some of the premolars analyzed from the modern human collection and the $H$. neanderthalensis collection, showed more than one root canal, they were all single rooted. In general, all the species with uniradicular premolars, showed some degree of apical convergence of the root canals at the longitudinal section of the root of the premolars (Table 4). In $H$. sapiens, there is a clear trend toward the convergence or narrowing of the root canals from the coronal to the apical third. However, in $H$. neanderthalensis and $H$. heidelbergensis, the convergence of the walls is small, particularly in the Sima de los Huesos sample where the walls are the most parallel of all the studied groups (Table 4). The similarities found between $H$. heidelbergensis from Sima de los Huesos and $H$. neanderthalensis would be in line with the similarities found in other dental traits (e.g., Bermúdez de Castro, 1987, 1988, 1993; Martinón-Torres, 2006; MartinónTorres et al., 2006, in press) and the proposed phylogenetic relationship between the Middle Pleistocene fossils from Europe and Neandertals (e.g., Arsuaga et al., 1997). This morphology is more pronounced in our Sima de los Huesos sample than in $H$. neanderthalensis and could be a reflection of a morphological particularity of this biological population.
All the specimens showed ellipsoid shapes in their pulp cavities at the CEJ plane with the exception of the $H$. heidelbergensis premolars, which had a circular shape. Following crown formation, epithelial cells continue to proliferate to the tooth apex and produce a tubular sheath known as Hertwig's epithelial root sheath (HERS) from which horizontal processes start to develop (Kupczik and Hublin, 2010). Root structure (single or multirooted) is determined by the shape and folding of this sheath (Kovacs, 1971). Deviations in the invagination process lead to variations in root morphologies and number (Wright, 2007; Kupczik and Hublin, 2010). The lack of convergence of the root canal walls and the circular shape of the CEJ plane, together with the measurements of the root canal volume and surface presented in Table 4, are traits related to the presence of very wide root canals in the $H$. heidelbergensis premolars. This might be related to the length of $H$. heidelbergensis roots, which were the longest on average of the entire sample (Table 3). As Kovacs (1971) stated, the length of the root depends on the rate at which the Hertwig's epithelial root sheath narrows. The lack of convergence of the root canal walls in $H$. neanderthalensis and particularly in our Sima de los Huesos sample could be a consequence of the same mechanism that is responsible of the taurodontism typically observed in the molars of these groups (e.g., Bermúdez de Castro et al., 2003; Kupczik and Hublin, 2010). In taurodont molars, the invagination of the interradicular processes is delayed or disrupted and the furcation of the roots is displaced towards the apex, resulting in an enlarged pulp cavity and lack of constriction (e.g., Jaspers and Witkop, 1980). The same process might be reflected in the LP4 of these two groups. Regarding ATE9-1, its narrower root canal in comparison with that of $H$. heidelbergensis and $H$. neanderthalensis (Figs. 2 and 3) may be reflecting that a root canal convergent to the apex is the primitive condition. The morphology of ATE9-1 root canal could be due to the postmortem deposited matrix and secondary dentine physiologically deposited through the life of the subjects (Benzer, 1948). However, we cannot eliminate the possibility that the morphology of ATE9-1 root canal could also be the result of pulp canal obliteration (calcific metamorphosis). This condition is characterized by the deposition of hard tissue within the root canal space; it is a sequela of tooth trauma which is developed more often in teeth following concussion and subluxation injuries (Oginni and Adekoya-Sofowora, 2007). The mechanism of canal obliteration is still unknown; it could be related to damage to the neurovascular supply of the pulp at the time of injury (Yaacob and Hamid 1986; Robertson, 1998). Indeed, as Martinón-Torres et al. (2011) suggest, Sima del Elefante mandible to which this tooth belongs to, present several pathological signs related to heavy and even traumatic masticatory habits. More specimens are needed in order to establish the polarity of this trait.

The Sima de los Huesos and San Pablo lower second premolar roots and pulp cavities revealed a clear morphological homogeneity. They all have a single root, with a single and wide root canal without ramifications; they all show circular external and internal CEJ planes and a slight apical convergence. Previous studies (Dahlberg 1951; Sofaer et al., 1972; Turner, 1986, 1989, 1990; Griffin, 1993) have shown that there is a correlation between biological distances and dental morphology and that this 
relationship can be used to determine the degree of relatedness among populations. All the human fossils from the Sima de los Huesos site were recovered from the same breccia unit, which consisted of clay-supported bones, blocks, and clasts (Bischoff et al., 1997). The relative morphological homogeneity of the $H$. heidelbergensis LP4 in both roots and root canals and the fact that all the individuals were deposited during the same sedimentation episode (Bischoff et al., 1997) supports the notion that they belong to the same biological population (e.g., Arsuaga et al., 1990; Bermúdez de Castro, 1993; Rosas, 1992).

The roots of the $H$. neanderthalensis premolars are shorter and wider on average than those of $H$. heidelbergensis which were the longest on average of the whole sample (Table 3). This is the reason why although $H$. heidelbergensis showed a higher average root volume, the areas of the planes of the root and the external root surface were higher on average in $H$. neanderthalensis.

The lack of significant differences observed between the measurements taken in $H$. heidelbergensis and $H$. neanderthalensis supports the theory of a close phylogenetic relationship between the hominins of AtapuercaSima de los Huesos and the late Pleistocene classic Neanderthals (e.g., Arsuaga et al., 1993, 1997; Bermúdez de Castro, 1993; Martinón-Torres, 2006; Gómez-Robles, 2008; Martinón-Torres et al., in press). The crown and the pulp chamber were not included in the quantitative measurements as they could be more affected by external factors such as aging, pathology, traumatic occlusion and tertiary dentine deposition than the root canals (Cohen and Hargreaves, 2008). As the closure of the root apex is related to the time that the tooth becomes functional, the category of wear of the tooth could serve as a proxy of the time that the tooth has been functional (functional age of the tooth). The presence of a category of wear higher than 1 (Molnar, 1971) means that the apex was formed for a period of time and the tooth has been functional for enough time to have secondary dentine deposited in the pulp cavity walls. Secondary dentine is deposited at a slower rate than primary dentine. Its production is continuous throughout the life of the tooth (Gómez and Campos, 2004) and consequently, the size of the pulp cavity is gradually reduced throughout the individual's lifetime (Prapanpoch and Cottone, 1992; Paewinsky et al., 2005). This fact could affect the measurements taken of the pulp cavity of the teeth with a category of wear higher than 1; future studies with modern humans and bigger sample sizes should address the exact impact or lack of impact of these factors in the internal measurements.

In summary, it has been found that the root morphologies identified in the $H$. antecessor sample from Gran Dolina-TD6 (2R: MB + DL with at least two [MB and $\mathrm{DL}]$ in ATD6-125 and three [B + M + DL] canals in ATD6-4) and the ATE9-1 specimen from Sima del Elefante (2T with a MB and DL canal) could suggest transitional root morphologies from the primitive conformations found in Australopithecus robustus and African early Homo (2R: M $+\mathrm{B}$ with two root canals in each root) to the derived condition of later Homo species (1R). $H$. heidelbergensis and $H$. neanderthalensis premolars showed small convergence of their root canals, but this tendency was highly marked in $H$. heidelbergensis premolars with very parallel walls, which could be a reflection of a morphological particularity of its biological population which showed very characteristic features in its root canals. Apart from the minimal apical convergence of the root canal walls, all the Sima de los Huesos specimens showed a circular shape of the pulp canal at the CEJ plane, whereas in the remaining groups the section was ellipsoid. These features correspond to long roots and wide root canals and could be related to the taurodontism observed in $H$. heidelbergensis molars. The morphological analyses of the pulp cavities showed an important homogeneity in the Sima de los Huesos sample supporting the fact that they represent the same biological population. This study was performed with small sample sizes and one tooth position to test the validity of the method proposed, future studies with larger sample sizes and different tooth positions will be needed to corroborate these findings.

\section{ACKNOWLEDGMENTS}

Teeth for this study were graciously donated by the Universidad de Burgos, personal donations from dentists and colleagues (Jorge Javier Villanueva, Elena Arnáiz, José Luis Ubierna, David Sánchez, Sara Manrique, Andoni Tarriño, Santiago Gil, and Concepción Moreno), and especially a large contribution from the members of the Spanish society of Periodontics and Osteointegration (SEPA). Neanderthal micro-CT scans were acquired from the NESPOS society, special thanks should be given to Priscilla Bayle and Roberto Machiarelli for their help and kindness. The authors also give special thanks to Ciarán Brewster and Ken Sawyer for the English edition. Thank you to Dr. Ruff, to the anonymous reviewers, and the associate editor who helped to improve the quality of the manuscript. This study benefitted greatly from contributions by the following individuals and institutions: the University of Granada, Pilar Fernández-Colón and Elena Lacasa from the Conservation and Restoration department of CENIEH (Burgos), Jesús Ángel Martín, David Herrera, Pablo E. Gil- Loyzaga, David Gil, Asier Gómez, Federico Simón, Emiliano Bruner, José Manuel de la Cuétara, Luis Tortosa, Paz Gil-Delgado, Javier Vicente, Laura Rodríguez, Elena Santos, Ana Gracia, Juan Luis Arsuaga, and the Atapuerca excavation and research team.

\section{LITERATURE CITED}

Abbott SA. 1984. A comparative study of tooth root morphology in the great apes, modern man and early hominids. Ph.D. Dissertation. University of London, London, United Kingdom.

Arsuaga JL, Carretero JM, Gracia A, Martínez I. 1990. Taphonomical analysis of the human sample from the Sima de los Huesos Middle Pleistocene site (Atapuerca/Ibeas Spain). Hum Evol 39:179-185.

Arsuaga JL, Martínez I, Gracia A, Carretero JM, Carbonell E. 1993. Three new human skulls from the Sima de los Huesos Middle Pleistocene site in Sierra de Atapuerca, Spain. Nature 362:534-537.

Arsuaga JL. Martínez I, Gracia A, Lorenzo C. 1997. The Sima de los Huesos crania (Sierra de Atapuerca, Spain). J Hum Evol 33:219-281.

Bailey SE. 2002a. A closer look at Neanderthal postcanine dental morphology: the mandibular dentition. Anat Rec New Anat 269:148-156.

Bailey SE. 2002b. Neandertal dental morphology: implications for modern human origins. Ph.D. Dissertation. Tempe: Arizona State University.

Bailey SE, Lynch JM. 2005. Diagnostic differences in mandibular P4 shape between Neandertals and anatomically modern humans. Am J Phys Anthropol 126:268-277. 
Bailey SE, Skinner MM, Hublin JJ. 2011. What lies beneath? An evaluation of lower molar trigonid crest patterns based on both dentine and enamel expression. Am J Phys Anthropol 145:505-518.

Bayle P, Braga J, Mazurier A, Macchiarelli R. 2009a. Dental developmental pattern of the Neanderthal child from Roc de Marsal: a high-resolution 3D analysis. J Hum Evol 56:66-75.

Bayle P, Braga J, Mazurier A, Macchiarelli R. 2009b. Brief communication: high-resolution assessment of the dental developmental pattern and characterization of tooth tissue proportions in the late Upper Paleolithic child from La Madeleine, France. Am J Phys Anthropol 138:493-498.

Bayle P, Macchiarelli R, Trinkaus E, Duarte C, Mazurier A, Zilhão J. 2010. Dental maturational sequence and dental tissue proportions in the early Upper Paleolithic child from Abrigo do Lagar Velho, Portugal. Proc Natl Acad Sci USA 107:1338-1342.

Bermúdez de Castro JM. 1987. Morfología comparada de los dientes humanos fósiles de Ibeas (Sierra de Atapuerca, Burgos). Estudios Geológicos 43:309-333.

Bermúdez de Castro JM. 1988. Dental remains from Atapuerca/ Ibeas (Spain) II. Morphology. J Hum Evol 17:279-304.

Bermúdez de Castro JM. 1993. The Atapuerca dental remains: new evidence (1987-1991 excavations) and interpretations. J Hum Evol 24:339-371.

Bermúdez de Castro JM, Nicolás ME. 1995. Posterior dental size reduction in hominids: the Atapuerca evidence. Am J Phys Anthropol 96:335-356.

Bermúdez de Castro JM, Rosas A, Nicolás ME. 1999. Dental remains from Atapuerca-TD6 (Gran Dolina site, Burgos, Spain). J Hum Evol 37:523-566.

Bermúdez de Castro JM, Martinón-Torres M, Sarmiento S, Lozano M. 2003. Gran Dolina-TD6 versus Sima de los Huesos dental samples from Atapuerca: evidence of discontinuity in the European Pleistocene populations? J Archaeol Sci 30:1421-1428.

Bermúdez de Castro JM, Martinón-Torres M, Rosas A, van der Made J, Carbonell E, Sarmiento S, Lozano M. 2004. The Atapuerca sites and their contribution to the knowledge of human evolution in Europe. Evol Anthropol 13:25-41.

Bermúdez de Castro JM, Pérez-González A, Martinón-Torres M, Gómez-Robles A, Rosell J, Prado L, Sarmiento S, Carbonell E. 2008. A new Early Pleistocene Hominin mandible from Atapuerca-TD6, Spain. J Hum Evol 55:729-735.

Bermúdez de Castro JM, Martinón-Torres M, Gómez-Robles A, Prado-Simón L, Olejniczak A, Martín-Francés L, Lapresa M, Carbonell E. 2011. The Early Pleistocene human mandible from Sima del Elefante (TE) cave site in Sierra de Atapuerca (Spain): a comparative morphological study. J Hum Evol 61:12-25.

Biggerstaff RH. 1969. The basal area of posterior tooth crown components: the assessment of within tooth variation of premolars and molars. Am J Phys Anthropol 31:163-170.

Bischoff JL, Fitzpatrick JA, León L, Arsuaga JL, Falguères C, Bahain JJ, Bullen T. 1997. Geology and preliminary dating of the Sima de los Huesos Chamber, Cueva Mayor of the Sierra de Atapuerca, Burgos, Spain. J Hum Evol 33:109-127.

Canalda C, Brau E. 2006. Endodoncia. Técnicas clínicas y bases científicas. Barcelona: Ed. Masson.

Carbonell E, Bermúdez de Castro JM, Arsuaga JL, Allue E, Bastir M, Benito A, Cáceres I, Canals T, Díez JC, van der Made J, Mosquera M, Ollé A, Pérez-González A, Rodríguez J, Rodríguez XP, Rosas A, Rosell J, Sala R, Vallverdú J, Vergés JM. 2005. An Early Pleistocene hominin mandible from Atapuerca-TD6, Spain. Proc Natl Acad Sci USA 102:5674-5678.

Carbonell E, Bermúdez de Castro JM, Parés JM, Pérez-González A, Cuenca-Bescós G, Ollé A, Mosquera M, Huguet R, van der Made J, Rosas A, Sala R, Vallverdú J, García N, Granger DE, Martinón-Torres M, Rodríguez XP, Stock GM, Vergès JM, Allué E, Burjachs F, Cáceres I, Canals A, Benito A, Díez C, Lozano M, Mateos A, Navazo M, Rodríguez J, Rosell J, Arsuaga JL. 2008. The first hominin of Europe. Nature 452:465-469.

Cohen S, Hargreaves KM. 2008. Pathways of the pulp. St. Louis: Elsevier-Mosby.
Condemi S. 2001. Les Néandertaliens De la Chaise (Abri BourgeousDelaunay). Comité des Travaux Historiques et Scientifiques.

Dahlberg A. 1951. The dentition of the American Indian. In: Papers on the physical anthropology of the American Indian. New York: Viking Fund. p138-176.

Dean C, Leakey MG, Reid D, Schrenk F, Schwartz GT, Stringer C, Walker A. 2001. Growth processes in teeth distinguish modern humans from Homo erectus and earlier hominins. Nature 414:628-631.

Gómez ME, Campos A. 2004. Histología y embriología bucodental. Madrid: Editorial Médica Panamericana.

Gómez-Robles A, Martinón-Torres M, Bermúdez de Castro JM, Prado L, Sarmiento S, Arsuaga JL. 2008. Geometric morphometric analysis of the crown morphology of the lower first premolar of hominins, with special attention to Pleistocene Homo. J Hum Evol 55:627-638.

Griffin M. 1993. Morphological variation of the Late Precontact and Contact Period Guale. Ph.D. Dissertation. Purdue University, Indiana, USA.

Harvati K, Panagopoulou E, Karkanas P. 2003. First Neanderthal remains from Greece: the evidence from Lakonis. J Hum Evol 45:465-473.

Hillson S. 1996. Dental anthropology. Cambridge: Cambridge University Press.

Jaspers MT, Witkop C. 1980. Taurodontism, an isolated trait associated with syndromes and X-chromosomal aneuploidy. Am J Hum Genet 32:396-413.

Kay RF. 1981. The nut-crackers: a new theory of the adaptations of the Ramapithecinae. Am J Phys Anthropol 55:141-151.

Kono R. 2004. Molar enamel thickness and distribution patterns in extant great apes and humans: new insights based on a 3-dimensional whole crown perspective. Anthropol Sci 112:121-146.

Korenhof CAW. 1961. The enamel-dentine border: a new morphological factor in the study of the (human) molar pattern. Proc Koninkl Nederl Acad Wetensch 64:639-664.

Kovacs I. 1971. A systematic description of dental roots. In: Dahlberg AA, editor. Dental morphology and evolution. Chicago: University of Chicago Press. p211-256.

Kupczik K, Hublin JJ. 2010. Mandibular molar root morphology in Neanderthals and Late Pleistocene recent Homo sapiens. J Hum Evol 59:525-541.

Kvaal SI, Kolltveit KM, Thomsen IO, Solheim T. 1995. Age estimation of adults from dental radiographs. Forensic Sci Int 74:175-185.

Lacruz RS, Bromage TG. 2006. Appositional enamel growth in molars of South African fossil hominids. J Anat 209:13-20.

Ludwig FJ. 1957. The mandibular second premolars: morphologic variation and inheritance. J Dent Res 36:263-273.

Macchiarelli R, Bondioli L, Debénath A, Mazurier A, Tournepiche JF, Birch W, Dean MC. 2006. How Neanderthal molar teeth grew. Nature 444:748-751.

Martin LB. 1985. Significance of enamel thickness in hominoid evolution. Nature 314:260-263.

Martinón-Torres M. 2006. Evolución del aparato dental en homínidos: estudio de los dientes humanos del Pleistoceno de la Sierra de Atapuerca (Burgos). PhD Dissertation. Universidad de Santiago de Compostela.

Martinón-Torres M, Bastir M, Bermúdez de Castro JM, Gómez A, Sarmiento S, Muela A, Arsuaga JL. 2006. Hominin lower second premolar morphology: evolutionary inferences through geometric morphometric analysis. J Hum Evol 50:523-533.

Martinón-Torres M, Martín-Francés L, Gracia A, Olejniczak A, Prado-Simón L, Gómez-Robles A, Lapresa M, Carbonell E, Arsuaga JL, Bermúdez de Castro JM. 2011. The Early Pleistocene human mandible from Sima del Elefante (TE) cave site in Sierra de Atapuerca (Spain): a paleopathological study. J Hum Evol 61:1-11.

Martinón-Torres M, Bermúdez de Castro JM, Gómez-Robles A, Prado-Simón L, Arsuaga JL. Morphological description and comparison of the dental remains from Atapuerca-Sima de los Huesos site (Spain). J Hum Evol, in press.

Maureille B, Rougier H, Houët F, Vandermeersch B. 2001. Les dents inférieures du néandertalien Regourdou 1 (site de Regourdou, commune de Montignac, Dordogne): analyses mét- 
riques et comparatives. The mandibular dentition of the Regourdou 1 Neandertal skeleton from Regourdou (Regourdou site, Montignac, Dordogne): metric and comparative analysis. Paleo 13:183-200.

Molnar S. 1971. Human tooth wear, tooth function and cultural variability. Am J Phys Anthropol 34:175-190.

Monge J MA, Frayer D, Radovčić J, editors. 2008. New insights on the Krapina Neandertals: 100 years since GorjanovićKramberger. Zagreb: Croatian Natural History Museum.

Oginni AO, Adekoya-Sofowora CA. 2007. Pulpal sequelae after trauma to anterior teeth among adult Nigerian dental patients. BMC Oral Health 7:11-15.

Olejniczak AJ. 2006. Micro-computed tomography of primate molars. Ph.D. Dissertation, Stony Brook University, New York, USA.

Olejniczak AJ, Grine FE. 2006. Assessment of the accuracy of dental enamel thickness measurements using microfocal Xray computed tomography. Anat Rec 288:263-275.

Paewinsky E, Pfeiffer H, Brinkmann B. 2005. Quantification of secondary dentine formation from orthopantomograms: a contribution to forensic age estimation methods in adults. Int $\mathrm{J}$ Legal Med 119:27-30.

Patte E. 1962. La dentition des Néanderthaliens. Paris: Masson et Cie.

Prapanpoch S, Cottone JA. 1992. Morphometric analysis of the dental pulp chamber as a method of age determination in humans. Am J Forensic Med Pathol 13:50-55.

Robertson A. 1998. A retrospective evaluation of patients with uncomplicated crown fractures and luxation injuries. Dent Traumatol 14:245-256.

Rosas A. 1992. Ontogenia y filogenia de la mandíbula en la evolución de los homínidos. Aplicación de un modelo de morfogénesis a las mandíbulas fósiles de Atapuerca. PhD Dissertation. Madrid: Universidad Complutense.

Rosas A, Martínez -Maza C, Bastir M, García -Tabernero A, Lalueza-Fox C, Huguet R, Ortiz JE, Juliá R, Soler V, de Torres T, Martínez E, Cañaveras JC,Sánchez-Moral Cuezva S, Lario J, Santamaría D, de la Rasilla M, Fortea J. 2006. Paleobiology and comparative morphology of a Late Neandertal sample from El Sidrón, Asturias, Spain. Proc Natl Acad Sci USA 103:19266-19271.

Scott RS, UP Bergstrom TS, Brown CA, Grine FE, Teaford MF, Walker A. 2005. Dental microwear texture analysis shows within-species diet variability in fossil hominins. Nature 436:693-695.

Shields ED. 2005. Mandibular premolar and second molar root morphological variation in modern humans: what root number can tell us about tooth morphogenesis. Am J Phys Anthropol 128:299-311.

Skinner MM, Wood BA, Boesch C, Olejniczak AJ, Rosas A, Smith TM, Hublin J-J. 2008. Dental trait expression at the enamel-dentine junction of lower molars in extant and fossil hominoids. J Hum Evol 54:173-186.
Skinner MM, Wood BA, Hublin JJ. 2009. Protostylid expression at the enamel-dentine junction and enamel surface of mandibular molars of Paranthropus robustus and Australopithecus africanus. J Hum Evol 56:76-85.

Smith TM, Toussaint M, Reid DJ, Olejniczak AJ, Hublin JJ. 2007. Rapid dental development in a Middle Paleolithic Belgian Neanderthal. Proc Natl Acad Sci USA 104:20220-20225.

Sofaer JA, Niswander JD, Maclean CJ, Workman PL. 1972. Population studies on southwestern Indian tribes. V. Tooth morphology as an indicator of biological distance. Am J Phys Anthropol 37:357-366.

Soares IJ, Goldberg F. 2002. Endodoncia: técnicas y fundamentos. Ed Panamericana.

Sprinz R. 1953. The linking tooth: a rare anomaly of a mandibular premolar. British Dent J 95:108-109.

Tafforeau P. 2004. Phylogenetic and functional aspects of tooth enamel microstructure and three-dimensional structure of modern and fossil primate molars. PhD Dissertation. Université de Montpellier II: Montpelieur, France.

Trinkaus E. 1978. Dental remains from the Shanidar adult Neanderthals. J Hum Evol 7:369-382.

Turner CG II. 1986. Dendrochronological separation estimates for Pacific Rim populations. Science 23:1140-1142.

Turner CG II. 1989. Late Pleistocene and Holocene population history of East Asia based on dental variation. Am J Phys Anthropol 73:305-321.

Turner CG II. 1990. Major features of sundadonty and sinodonty, including suggestions about East Asian microevolution, population history, and Late Pleistocene relationships with Australian Aboriginals. Am J Phys Anthropol 82:295-317.

Turner CG II, Nichol CR, Scott GR. 1991. Scoring procedures for key morphological traits of the permanent dentition: The Arizona State University Dental Anthropology System. In: Kelley M, Larsen C, editors. Advances in dental anthropology. New York: Wiley-Liss. p13-31.

Uytterschaut HT, Wood BA. 1989. Dental morphology: characterization and dentification of Australopithecines and Homo habilis. In: Hominidae. Proceedings of the Second International Congress of Human Paleontology. Milan: Editoriale Jaca. p183-188.

Vandermeersch B, Trinkaus E. 1994. The postcranial remains of the Régordou 1 Neandertal: the shoulder and arm remains. J Hum Evol 28:439-476.

Wood BA, Abbot SA, Uytterschaut H. 1988. Analysis of the dental morphology of Plio-Pleistocene hominids. IV. Mandibular postcanine root morphology. J Anat 156:107-139.

Wood BA, Uytterschaut H. 1987. Analysis of the dental morphology of Plio-Pleistocene hominins. III. Mandibular premolar crowns. J Anat 154:121-156.

Wright T. 2007. The molecular control of and clinical variations in root formation. Cells Tissues Organs 186:86-93.

Yaacob HB, Hamid JA. 1986. Pulpal calcification in primary teeth: a light microscopy study. J Pedod 10:254-64. 